\title{
If She Weighs the Same as a Duck, Then She's a Witch: Using a Classic Monty Python Movie to Stimulate Transfer of Learning in Engineering Mechanics
}

\author{
Stephen Ressler, Joseph P. Hanus \\ United States Military Academy
}

Transfer of Learning

Much of the literature on teaching and learning emphasizes the importance of transfer of learning. This concept is based on a simple premise - that the information, concepts, and problem-solving strategies students learn in the classroom do not become fully operative until the learning can be transferred to entirely new and unfamiliar contexts. When transfer of learning happens, students can effectively apply new learning to the solution of problems unlike those experienced in the classroom environment. As a National Research Council report notes, "A major goal of schooling is to prepare students for flexible adaptation to new problems and settings." [1] This is particularly true for engineering graduates, who will likely encounter many real-world situations that are vastly different from the types of problems they learned to solve as students. Thus transfer of learning should be a explicit objective of engineering education and an integral component of instructional design.

All too often, however, it is not. Engineering educators generally recognize, at least implicitly, that transfer of learning is important. Many evaluate it, for example, by using conceptually challenging exam questions that are substantially different from problems that students have worked in class and on homework assignments. However, for many students - particularly immature learners - the ability to transfer learning does not come naturally or easily. (Witness students' common complaint that "the exam questions were nothing like our homework problems.") Like most skills, transfer of learning must itself be learned-preferably before it is evaluated. And as with most skills, an effective way to learn how to transfer learning is through practice and feedback.

The Project

This paper describes a novel attempt to stimulate transfer of learning in an introductory course in Statics and Dynamics at the U.S. Military Academy. The authors developed a rather unorthodox course project that was explicitly designed to provide students with an opportunity to practice the application of newly learned concepts in an unfamiliar context.

The Statics and Dynamics course is taken by second-semester sophomores and first-semester juniors at the Academy. The student population includes approximately equal numbers of engineering majors and non-engineering majors (to include many humanities and social sciences majors). Thus the course must address a broad range of student capabilities and motivations. In practically all cases, students are taking this course as their first engineering course; thus, we feel a special obligation to ensure that the course provides students with a positive, enjoyable 
learning experience — one that will motivate them for further engineering studies and set them on a path to success.

Consistent with that goal, we implemented a small course-end project during the spring semester of Academic Year 2001-2002, with the following specific objectives:

- Provide students with an opportunity to apply a major course concept to solve a problem in an unfamiliar context.

- Allow students to choose from a broad range of possible problems to solve.

- Provide an enjoyable problem-solving experience as a culminating course project.

In this project, teams of two students each were asked to do the following:

- View the movie "Monty Python and the Holy Grail," a classic 1975 spoof of Arthurian legend that continues to attract a strong following among today's college students.

- Select a scene that illustrates a non-trivial application of any statics or dynamics concept covered in the course.

- Perform an engineering analysis of a physical object or device from that scene. The analysis was required to include: (1) a conceptual model of the object, represented as a sketch or diagram; (2) reasonable assumptions of the relevant engineering properties (e.g., weights, dimensions, coefficients of friction, types of support); (3) computations to determine some aspect of the object's performance; and (4) an explanation of the results and their significance.

- Prepare a written report detailing the analysis.

This assignment facilitated transfer of learning by requiring students, first, to find practical applications of engineering mechanics in a context that one would not normally associate with engineering; and, second, to model and analyze an ill-defined situation, to include the formulation of reasonable quantitative assumptions for engineering properties. To reinforce the intent of the exercise, grades were based primarily on the appropriateness of the selected topic and the quality of the engineering analysis, with some credit awarded for the quality of the written report and bonus points for creativity. The allocation of points for the project represented less that $3 \%$ of the total course grade. Thus students were encouraged to take a risk in the selection of their project topic, without having to worry about excessive damage to their grade if their choice proved to be unwise.

To facilitate the project, we scheduled two opportunities for students to view a videotape of the movie, at times when they were not likely to have conflicting activities. In practice, many students were already quite familiar with the film and, to acquire the information necessary to do the assignment, only needed to consult one of the many websites devoted to Monty Python. ${ }^{2}$ The teams had approximately two weeks to complete the analysis and produce the project report. 
Project Assessment

In general, students reacted to this project with great enthusiasm - if only because the assignment was so unlike anything they had ever done in their previous coursework. We did not formally assess their perceptions of this specific project; however, their responses to our course-end survey reflected strong outcomes in the specific areas that this project targeted-motivation to learn, critical thinking, and the instructor's use of effective techniques. The results are summarized in Table 1 below. Student responses were scored on a five-point Likert scale, with 1 indicating strong disagreement and 5 indicating strong agreement.

\begin{tabular}{|l|c|c|}
\hline \multicolumn{1}{|c|}{ Survey Question } & $\begin{array}{c}\text { Course } \\
\text { Average }\end{array}$ & $\begin{array}{c}\text { USMA } \\
\text { Average }\end{array}$ \\
\hline My motivation to learn increased because of this course. & 4.35 & 3.92 \\
\hline The instructor stimulated my thinking. & 4.46 & 4.22 \\
\hline In this course my critical thinking ability increased. & 4.35 & 4.06 \\
\hline The instructor used effective techniques. & 4.71 & 4.21 \\
\hline
\end{tabular}

Table 1. Student responses on selected course-end survey questions for Statics and Dynamics, in comparison with averages for the entire student population, Term 2, Academic Year 2001-2002.

It must be said, however, that these student responses do not differ significantly from those of prior academic years, before this particular project was offered. Thus the course survey data only prove conclusively that this project did no harm.

A far better indicator of the value of the project can be found in the actual products of our students' efforts. The students' solutions to the project exhibited great variety and reasonably high quality. A few representative examples follow.

Where'd You Get the Coconuts?

Early in "Monty Python and the Holy Grail," King Arthur arrives at the gates of a castle, with the intention of inviting the lord to join him at Camelot. He is greeted by two guards on the castle ramparts. The guards become involved in a tangential discussion about whether or not a bird might be able to carry a coconut while flying. One suggests that two birds might work together, with the coconut suspended between them on a strand of creeper. Unable to get the guards' attention, Arthur gives up in frustration and gallops off, his faithful servant Patsy

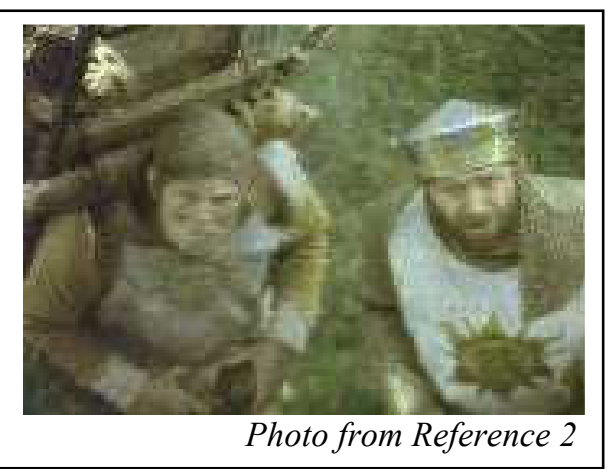
simulating the sound of horses' hooves by banging two coconut halves together.

One student team analyzed the subject of the guards' discussion - two birds attempting to carry a coconut. The team modeled the problem as shown in Figure 1 below. The equilibrium analysis was accompanied by a convincing argument that, given the need for the two birds to maintain a certain clearance between them, and given a creeper of reasonable length, each bird would need 
to generate lift approximately equal to the weight of the coconut. Thus he concluded that there was no advantage in having two birds attempt the job as a team effort.

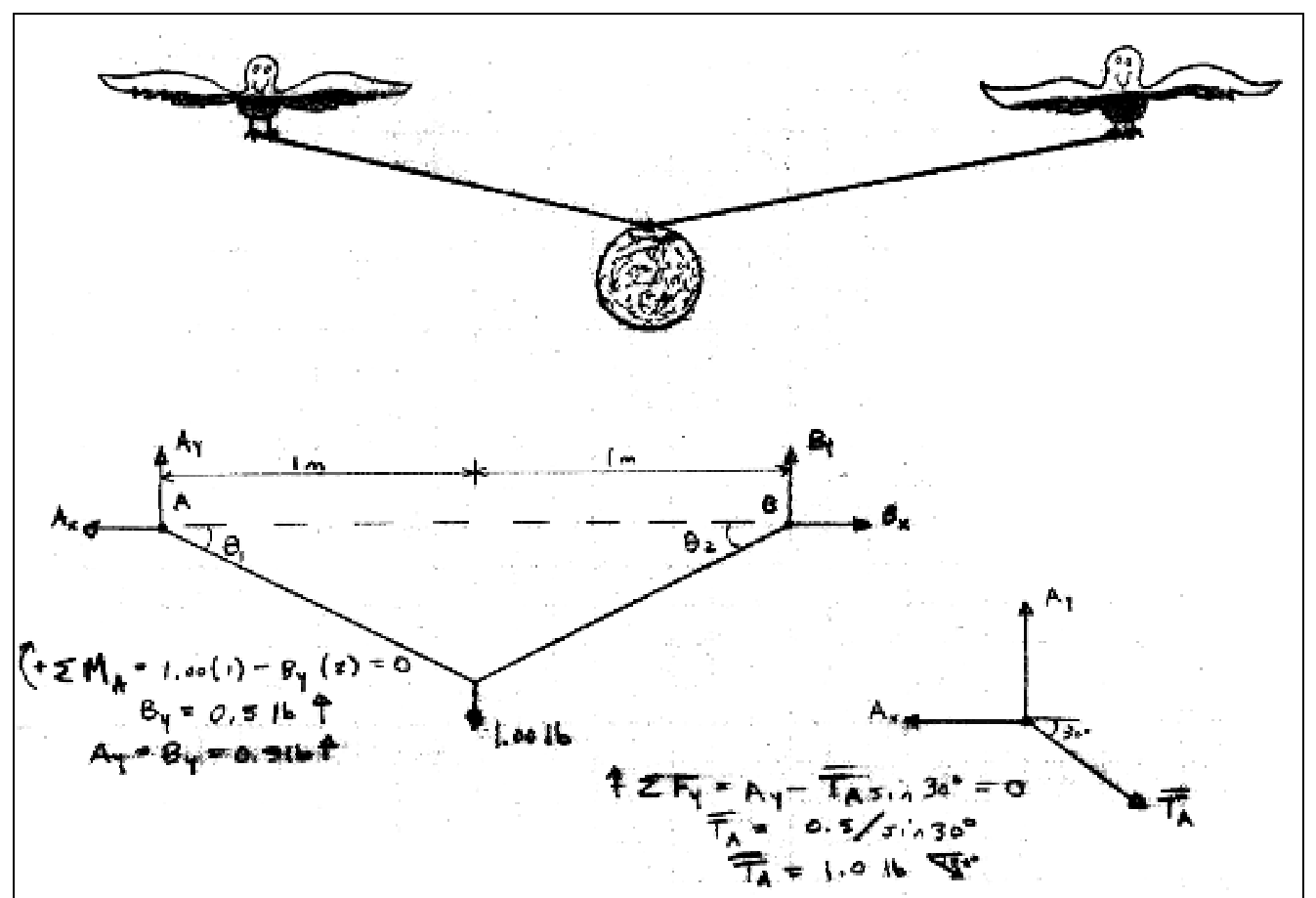

Figure 1. A student's static analysis of two swallows attempting to lift a coconut.

How Do You Know She is a Witch?

In one of the most famous scenes from the movie, a mob of peasants seizes a young woman whom they accuse of being a witch. They bring her to Sir Bedivere, who is asked to pass judgment in her case. Through a hilariously illogical exercise of logical reasoning, Sir Bedivere concludes that the woman is a witch if she weighs the same as a duck. He places the woman and a duck on a large, two-pan balance scale. The scale balances, and the townspeople jubilantly carry the witch off to be burned.

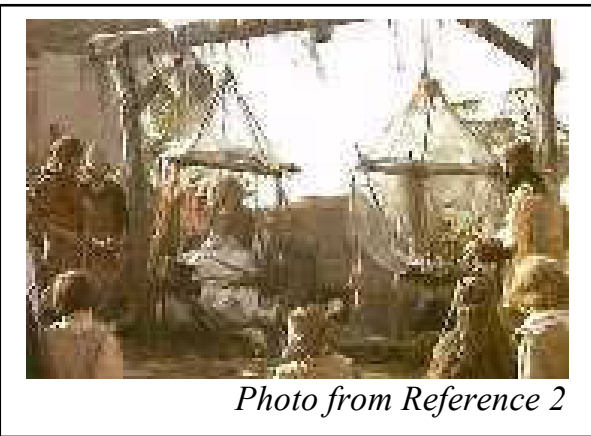

One student team conducted a static analysis of the scale in this scene. (Figure 2) Although this problem appears to be relatively trivial, the students' solution was effective because it considered the rather complex rope-and-pulley system used by the scale. The team concluded that, if the woman and the duck actually weighed the same, the scale could be placed in any positiontwo would not necessarily move to the same elevation, as shown in the scene. 


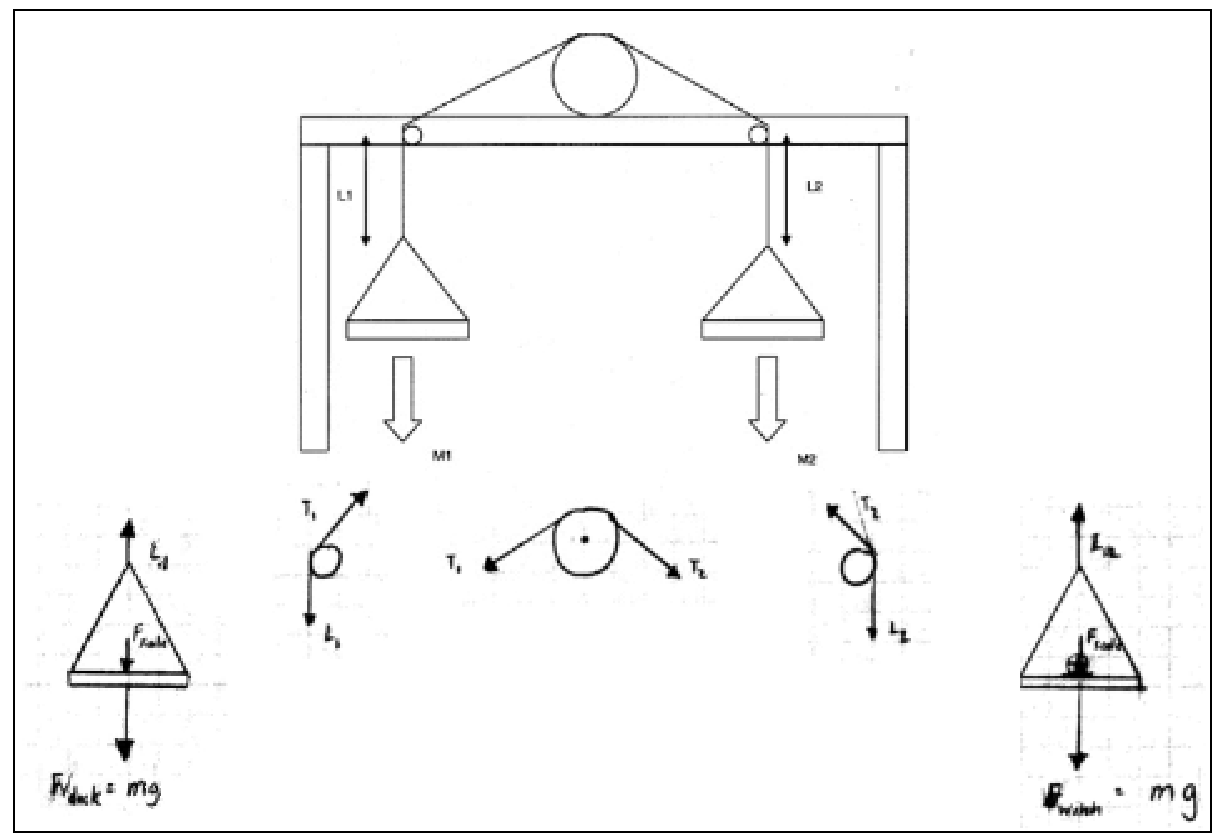

Figure 2. A student's analytical model of Sir Bedivere's scale.

The Trojan Rabbit

As the quest for the Holy Grail continues, Arthur comes upon a castle inhabited by a group of obnoxious Frenchmen. The Frenchmen claim to have possession of the grail but will not allow Arthur to "come up and have a look." Arthur's knights concoct a plan to gain entry into the castle by building a large, wheeled wooden rabbit - a Pythonesque equivalent of the Trojan Horse.

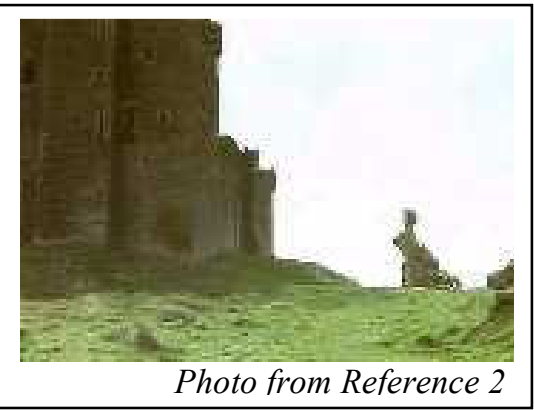

One student team performed a dynamic analysis of this scene, to determine the acceleration of the wooden rabbit in response to the force exerted by four knights pushing it up a ramp to the castle gate. (Figure 3) 

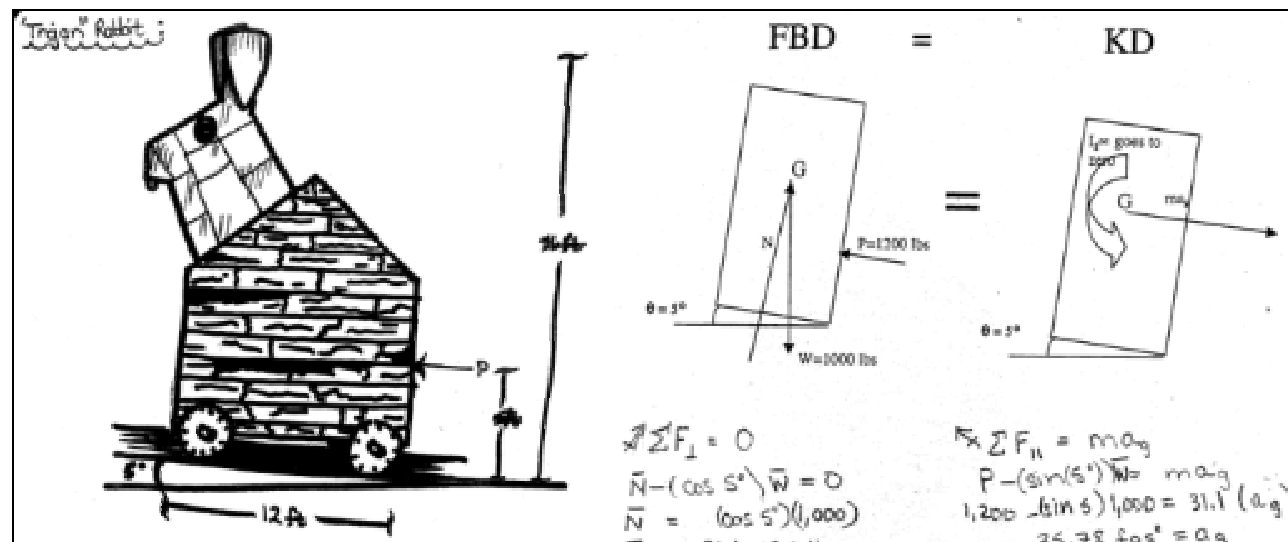

$\mathbb{3} \leq \mathrm{F}_{1}=0$

$\bar{N}-\left(\cos 5^{\circ}\right) \bar{W}=0$

$\bar{N}=(\cos 5)(1,000)$

$\bar{N}=966.995164,9$

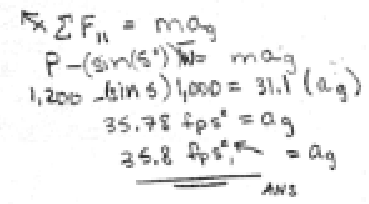

Figure 3. Dynamic analysis of the Trojan Rabbit, propelled by Arthur's knights.

The Bridge of Death

In the next-to-last scene of the movie, the knights must cross a dilapidated rope bridge spanning the Gorge of Eternal Peril. Several student teams performed a static analysis of this bridge. They estimated the span length and sag, assumed the weights and positions of the knights, and computed the force in the ropes. (Figure 4)
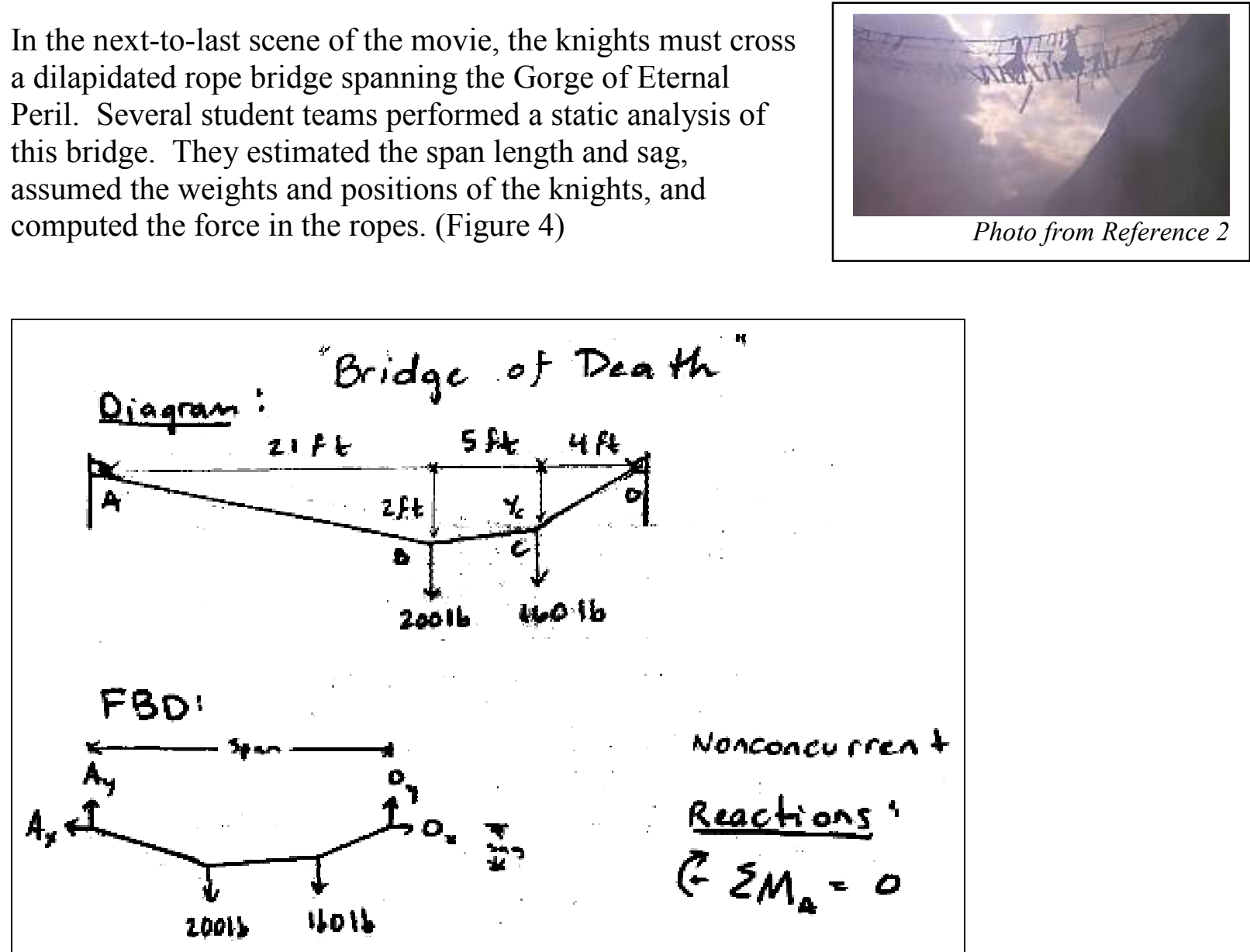

Figure 4. A portion of a student's static analysis of the Bridge of Death. 


\section{Conclusion}

These examples clearly demonstrate successful transfer of learning. In a context that one would normally not associate with engineering, the students have successfully identified situations to which their classroom instruction in engineering mechanics can be applied; and they have successfully modeled, analyzed, and drawn well-reasoned conclusions about those situations. The student solutions (particularly the narratives that accompany their calculations) also demonstrate considerable enthusiasm for this rather unorthodox homework requirement. The success of this project suggests that the "new and unfamiliar contexts" necessary for stimulating transfer of learning need not be confined to traditional engineering problems.

\section{References}

1. Bransford, John D., Ann L. Brown, and Rodney R. Cocking, ed. How People Learn: Brain, Mind, Experience, and School. Washington, D.C.: National Research Council, 2001.

2. "Monty Python's Flying Circus in Australia - World's Most Accurate Script," $<$ http://arago4.tn.utwente.nl/stonedead/main.html $>$, accessed January 11, 2004.

\section{STEPHEN J. RESSLER}

Colonel Stephen Ressler, P.E., is Professor and Deputy Head of the Department of Civil and Mechanical Engineering at the U. S. Military Academy. He teaches structural engineering and currently serves as Past Chair of the ASEE Civil Engineering Division.

JOSEPH P. HANUS

Major Joseph P. Hanus is Deputy Commander of the Galveston District, U.S. Army Corps of Engineers. He previously served as Assistant Professor in the Department of Civil and Mechanical Engineering at the U.S. Military Academy. 